\title{
Diagnostic Evaluation of Adenosine Deaminase (ADA) Test in the Early Diagnosis of Tuberculous Meningitis.
}

\author{
Kairavi. J. Desai, Saklainhaider. S. Malek, Navin. I. Shah, Pranay. K. Shah, Parthesh. K. Joshi, Jigna. K. Dave \\ Department of Microbiology, Govt. Medical College, Jail Road, Behind ST Bus Stand, Bhavnagar-364001. Gujarat.
}

\section{A B STRACT}

Objective: Tuberculous meningitis (TBM) is the commonest form of neurotuberculosis caused by Mycobacterium tuberculosis bacilli (MTB). The diagnosis of TBM is often difficult. A reliable, cost effective and rapid diagnostic test, which can be performed in any routine laboratory, could be of help in the diagnosis of TBM. In the present study we measured the adenosine deaminase (ADA) activity in cerebrospinal fluid (CSF) of TBM and non-TBM patients. Method: ADA activity in CSF was determined according to a method based on the modified Berthlot reaction, which is the formation of a colour indophenol complex from ammonia liberated from adenosine, and quantified spectrophotometrically. Results: ADA activity was studied in CSF of 45 cases of tuberculous meningitis, 20 cases of pyogenic meningitis and 20 controls (patients without any neurological disorders who were given spinal anaesthesia). The mean ADA activity was $13.43 \pm$ $4.76,8.23 \pm 2.91$ and $2.64 \pm 1.57 \mathrm{IU} / \mathrm{L}$ in tuberculous meningitis, pyogenic meningitis and controls respectively. The higher level of ADA in tuberculous meningitis was statistically significant $(p<0.0001)$. The sensitivity and specificity of ADA test in CSF at cut-off $10 \mathrm{U} / \mathrm{L}$ was $100 \%$ and $93.75 \%$ respectively. Conclusion: This study demonstrated that adenosine deaminase activity in CSF, a relatively inexpensive and easy procedure, can be of great value in the diagnosis of tuberculous meningitis. This test can be performed in any routine laboratory where more sophisticated methods are not available.

Key words: Adenosine deaminase, meningitis and cerebrospinal fluid

\section{INTRODUCTION}

Tuberculosis (TB) is one of the leading causes of mortality and morbidity in developing countries. The World Health Organization Reports put to the record that globally, approximately 16 millions people are suffering from active TB with an estimated 8.5 million developing active TB each year, resulting in approximately 2 million deaths. ${ }^{1}$ Tuberculous meningitis (TBM) is an endemic disease among socioeconomically disadvantaged communities in both developing and developed countries. ${ }^{2}$ In India, nearly 5 lakh people die due to tuberculosis each year. It represents $8.3 \%$ of childhood tuberculosis (TB). ${ }^{3}$ The importance of this disease has increased since there is emergence of acquired immuno-deficiency syndrome (AIDS) and multidrug resistant $\mathrm{TB}^{4}$

Tuberculous meningitis (TBM), the most dangerous form of extra pulmonary TB occurs in $7-12 \%$ of TB patients in

Address for correspondence:

Mobile: 098254691

E-mail: drkairavi@yahoo.in

DOI: 10.5530/ijmedph.2.2011.3 developing countries. Delay in diagnosis and institution of proper treatment is directly related to poor outcome and sequalae, which may be seen in $20-25 \%$ of cases. $^{5}$ The diagnosis of TBM is complicated as it causes various clinical manifestations, which overlap with those of other chronic diseases of the central nervous system (CNS) such as viral and pyogenic meningitis. ${ }^{6}$ The initiation of anti-TB medication in suspected TBM patients can often be delayed because of a lack of confidence in the presently available laboratory tests. ${ }^{7,8}$ Most of the tests developed for the early diagnosis of TBM are not sensitive ${ }^{9}$ and although some other tests are useful, they may not be affordable for routine use. ${ }^{10,11}$

A reliable and rapid diagnostic test, which can be performed in any standard laboratory, could be of help in diagnosis of TBM. Any test which facilitates a correct and rapid diagnosis of tuberculous meningitis should be very valuable. The definitive diagnosis of tuberculous meningitis depends on the detection of acid fast bacillus and culture of Mycobacterium tuberculosis in cerebrospinal fluid. However, culture is positive with varying degree and the facility is not always available. The characteristic CSF cytological and biochemical changes are also variable and may even be absent. ${ }^{12}$ 
Adenosine deaminase (ADA) is an enzyme that catalyzes the deamination of adenosine, forming inosine in the process. ${ }^{13}$ The chief physiological function of $\mathrm{ADA}$ is related to lymphocytic proliferation and differentiation. ${ }^{14}$ As a marker of cellular immunity, activity is found to be elevated in those diseases in which there is a cell-mediated immune response. ${ }^{15}$ The present study was conducted to confirm the usefulness of adenosine deaminase assay for diagnosis of tuberculous meningitis.

\section{MATERIALS AND METHOD}

This diagnostic study was conducted from January 2008 to December 2009. The ADA activity was estimated in 85 cases which include 45 TBM patients, 20 pyogenic meningitis and 20 control (patients without any neurological disorders who were given spinal anaesthesia) cases. The lumbar puncture (LP) was performed by trained medical officer in medicine ward of the same hospital. Informed consents were obtained from the patients and/ or their guardians prior to performing the LP procedure. The TBM patients were confirmed by clear signs and symptoms with AFB and/or culture positivity for bacteria or good response to antituberculous drugs. In pyogenic meningitis, the presence of other bacterial infection was confirmed by culture or staining smears positivity. The control cases included those who had no evidence of central nervous system (CNS) disorder or bacterial/viral infections. This study was approved by the Ethical Review Committee.

Adenosine deaminase (ADA) activity assay: ADA activity was assayed on the same day of the collection of CSF samples. The ADA activity was measured by the spectrophotometric method described by Guisti and Galanti. ${ }^{16}$ Ammonia forms under treatment of adenosine

Table 1: Comparison of CSF ADA levels in different
groups

Table 2: ADA test positivity in reference to culture

\section{CULTURE}

\begin{tabular}{lccc}
\hline ADA test cut-off & Positive & Negative & Total \\
\hline$>10 \mathrm{U} / \mathrm{L}$ & 13 & 2 & 15 \\
$<10 \mathrm{U} / \mathrm{L}$ & 0 & 30 & 30 \\
Total & 13 & 32 & 45 \\
\hline
\end{tabular}

to adenosine deaminase present in sample to give an intensely blue indophenol with sodium hypochlorite and phenol in alkaline solution as determined by modification Berthelot's reaction. Sodium nitroprusside is used as the catalyst. The ammonia concentration is directly proportional to the absorbance of the indophenols measured at wavelength $570 \mathrm{~nm}$. ADA activity was expressed as international unit (IU/L). For this ADA activity assay ADA - MTB Kit was used developed by Tulip Diagnostic Lab., India.

\section{STATISTICAL ANALYSIS}

Data were represented as Mean \pm SD and statistical analysis was done. By applying chi-square test $p$-value $<0.0001$ was established as statistically highly significant.

\section{RESULTS}

Table 1 gives the ADA values in the various groups. The mean ADA activity was $13.43 \pm 4.76,8.23 \pm 2.91$ and $2.64 \pm 1.57 \mathrm{IU} / \mathrm{L}$ in tuberculous meningitis, pyogenic meningitis and controls respectively. The higher level of $\mathrm{ADA}$ in tuberculous meningitis was statistically significant $(p<0.0001)$

Out of 45 TBM patients, 13 were confirmed TBM and the rest 32 cases belonged to clinical TBM. The mean CSF ADA activity in the confirmed TBM (14.5 IU/1) was significantly raised $(\phi<0.001)$ as compared to clinical TBM group. (7.83 IU/1).

Table 2 shows comparison of ADA test with culture. From Table 2, the sensitivity and specificity of ADA test in CSF at cut-off $10 \mathrm{U} / \mathrm{L}$ was $100 \%$ and $93.75 \%$ respectively. Positive predictive value of the ADA test is $86.66 \%$ and negative predictive value is $100 \%$.

\begin{tabular}{lcc}
$\begin{array}{l}\text { Table 3: shows distribution of TB meningitis cases } \\
\text { according to sex. }(\boldsymbol{n}=\mathbf{4 5})\end{array}$ \\
\hline Sex & Frequency & Percent \\
\hline F & 21 & $46.7 \%$ \\
M & 24 & $53.3 \%$ \\
\hline
\end{tabular}

Table 4: shows distribution of TB meningitis cases according to age. $(n=45)$

\begin{tabular}{lcc}
\hline \multicolumn{1}{c}{ Age } & Frequency & Percentage \\
\hline 1 to 15 & 39 & $86.7 \%$ \\
16 to 30 & 2 & $4.4 \%$ \\
31 to 45 & 3 & $6.7 \%$ \\
$>45$ & 1 & $2.2 \%$ \\
\hline
\end{tabular}




\section{DISCUSSION}

Most developing countries have the dubious distinction of having higher prevalence and incidence of tuberculosis and lack of well equipped laboratory services for proper diagnosis of tubercular meningitis. Early confirmatory diagnosis of TBM is difficult to establish because of its pleomorphic clinical presentation. ${ }^{17}$ Delayed diagnosis and treatment may be associated with many serious CNS complications. ${ }^{18}$ The most commonly used laboratory method for the definitive diagnosis of TBM is to demonstrate the presence of tubercle bacilli either by smear and/or culture. However, direct smear methods are often negative in CSF samples and culturing of MTB takes 4-6 weeks to show the growth. ${ }^{19,20}$

Although many sensitive tests involving molecular diagnostics have been available for rapid diagnosis of TB, yet, such a technology is not available in many developing countries. The estimation of ADA activity in body fluid therefore serves as a good and reliable tool in the diagnosis of TB pleural effusion and tubercular meningitis as well as their management especially when other clinical laboratory tests are negative within sensitive limit. ${ }^{21}$

Newer method such as those involving amplification of bacterial DNA by the PCR is incompletely assessed and not available for widespread use in most hospitals of the developing countries. The sensitivity of the PCR technique varies from $33.0 \%$ to $90.0 \%$ with a specificity of $88.0 \%$ to $100.0 \%{ }^{22}$ Various immunoassays such as antigen and/ or Ab detection in CSF samples have been developed with variable sensitivities and specificities. ${ }^{12,15,17}$

The result of the present study showed that mean CSF ADA level in TBM patients (13.43 U/L) was significantly raised $(P<0.0001)$ as compared to pyogenic meningitis and controls; a finding similar to that of other studies. $^{23,24,25,12}$

In the present study, a cut-off CSF ADA level of $>10 \mathrm{U} / \mathrm{L}$ was considered for the diagnosis of TBM with sensitivity and specificity of 100 and 93.75 per cent, respectively. Rajendra Prasad et al ${ }^{12}$ shows that sensitivity and specificity of ADA test for diagnosis of tuberculous meningitis was $100 \%$ and $97.87 \%$ respectively. OP Mishra et $\mathrm{al}^{26}$ said that a cut off CSF ADA level of $>5 \mathrm{IU} / \mathrm{L}$ was consider for the diagnosis of tubercular meningitis, and the ADA test had sensitivity and specificity of $89 \%$ and $92 \%$ respectively. Gambhir et $\mathrm{al}^{27}$ reported a low sensitivity of $44.0 \%$ and specificity of $75.0 \%$ for ADA test with a cut off value $8 \mathrm{IU} / \mathrm{L} / \mathrm{min}$, which showed overlap between TBM and non-TBM patients, especially for infectious neurological disorders like pyogenic meningitis.
Verajit et al ${ }^{28}$ identified a CSF ADA level of $15.5 \mathrm{IU} / \mathrm{L}$ as the cut off value with a sensitivity of $75 \%$ and a specificity of $93 \%$, lower sensitivity in this study may be due to higher value of cut-off for ADA test used. N.Selvakumar et $\mathrm{al}^{29}$ shows that sensitivity and specificity of ADA test in tuberculous meningitis is about $96 \%$ and $82 \%$ respectively.

In conclusion, $\mathrm{ADA}$ estimation in the CSF is simple, inexpensive and a rapid method to help the physician make an early diagnosis of tuberculous meningitis. This test should be done as a routine laboratory test on the CSF in areas with similar incidences of tuberculous meningitis exist.

\section{REFRENCES}

1. WHO reports 2003, Global TB control, surveillance, planning, financing; communicable diseases, WHO, Geneva pp-1.

2. Mastroianni, C.M., Paolotti, F., Lichtrer, M.D., Agostino, C., Vullo, V. and Delia, S. (1997) Cerebrospinal fluid cytokines in patients with tuberculous meningitis. Clin Immunopathology 84, 171-176.

3. Tandon, P.N. (1999) Neurotuberculosis: Clinical aspects. In: Neurology in Tropics. Chopra, J.S. and Sawhney, I.M.S. (eds.) Churchill Livingstone Ltd. 358-389.

4. Thweites, G., Chan, T.T.H., Mai, N.T.H. et al. (2000) Tuberculous meningitis. J Neurol Neurosurg and Psychait 68, 289-299.

5. Garcia-Monco, J.C. (1999) CNS Tuberculosis. In: Neurologic Clinics. Marra, C.M. (ed.). 17(4), 737-760.

6. Kashyap RS, Biswas SK, Agarwal N, Chandak N, Purohit HJ, Taori GM, Daginawala HF: Significance of $30 \mathrm{KD}$ protein marker as diagnostic marker in CSF of tuberculous meningitis. Ann Ind Acad Neurl 2001, 4:197-201.

7. Kashyap RS, Kainthla RP, Purohit HJ, Chandak N, Agarwal N, Taori GM, Daginawala HF: Rapid diagnosis of tuberculous meningitis using the simple Dot ELISA method. Med Sci Monit 2003,9:123-126.

8. Kashyap RS, Biswas SK, Purohit HJ, Chandak N, Agarwal N, Taori GM, Daginawala HF: Application of Mancini technique as a diagnostic test in CSF of tuberculous meningitis patients. Med Sci Monit 2002, 8:95-98.

9. Kilpatrick ME, Girgis NI, Yassin MW, Abu el Ella AA: Tuberculous meningitis - clinical and laboratory review of 100 patients. J Hyg (London) 1986, 96:231-238.

10. Kashyap RS, Kainthla RP, Satpute RM, Agarwal NP, Chandak NH, Purohit HJ, Taori GM, Daginawala HF: Differential diagnosis of tuberculous meningitis from partially treated cases of pyogenic meningitis by cell ELISA. BMC Neurology 2004, 4:16.

11. Radhakrishnan VV, Mathai A: Detection of Mycobacterium tuberculosis antigen 5 in cerebrospinal fluid by inhibition ELISA and its diagnostic potential in tuberculous meningitis. J Infect Dis 1991, 163:650-652.

12. Prasad R, Kumar A, Khanna BK et al. Adenosine deaminase activity in cerebrospinal fluid for diagnosis of tuberculous meningitis. Indian J Tub 1991; 38:99-102.

13. Fox IH, Kelly WN:The role of adenosine deaminase and 2'deoxyadensoine in mammalian cells. Ann Rev Biochem 1978, 47:655-686.

14. Erel O, Kocyigit A, Gurel MS, Bulut V, Seyrek A, et al.: Adenosine Deaminase activities in sera, lymphocytes and granulocytes in patients with cutaneous Leishmaniasis. Mem Inst Oswaldo Cruz, Rio de Janeiro 1998, 93:491-494.

15. Galanti B, Nardiello S, Russo M, Fiorentino F: Increased lymphocyte adenosine deaminase in typhoid fever. Scand J Infect Dis 1981, 13:47-50.

16. Guisti G, Galanti B. Colorimetric method. In: Bergmeyer H ed Methods of enzymatic analysis. $3^{\text {rd }}$ ed Weinheim: Verlag Chemic 1974, 315-23.

17. Kashyap RS, Biswas SK, Purohit HJ et al. Application of Mancini technique as a diagnostic test in CSF of tuberculous meningitis patients. Med Sci Monnit 2002; 8:95-8. 
18. Kennedy DH, Fallon RJ. Tuberculous meningitis. JAMA 1979, 241:264-68.

19. Thwaites G, Chau TT, Mai NT, Drobniewski F, McAdam K, Farrar J. Tuberculous meningitis. J Neurol Neurosurg Psychiatry 2000; 68:289-99.

20. Mathai A, Radhakrishnan VV, Sarada C, George SM. Detection of heat stablemycobacterial antigen incerebrospinal fluid by Dot-Immunobinding assay. Neurol India 2003; 51:52-4.

21. Lamsal M, Gautam N, Bhatta N, Majhi S, Baral N, Bhattacharya SK. Diagnostic utility of adenosine deaminase (ADA) activity in pleural fluid and serum of tuberculous and non-tuberculous respiratory disease disease patiens. Southeast Asian J Trop Med Public Health 2007; 38:263-9.

22. Blake J, Berman P. The use of adenosine deaminase assays in the diagnosis of tuberculosis. S Afr Med J 1982; 62:19-21.

23. Ribera E, Martinez-Vazquez JM, Ocana I, Segura RM, Pascual C. Activity of adenosine deaminase in cerebrospinal fluid for the diagnosis and follow-up of tuberculous meningitis in adults. J Infect Dis 1987; 155:603-7.
24. Pettersson T, Klockars M, Weber TH, Somer H. Diagnostic value of cerebrospinal fluid adenosine deaminase determination. Scand J Infect Dis 1991; 23:97-100.

25. Segura RM, Pascual C, Ocana I, et al. Adenosine deaminase in body fluids: a useful diagnostic tool in tuberculosis, d i n Biochem 1989; 22:141-8.

26. OP Mishra, $V$ Loiwal, $Z$ Ali, et al. CSF ADA activity for the diagnosis tuberculous meningitis in children. J of Trop Pedia 1996; 42:129-132.

27. Gambhir IS, Mehta M, Singh DS, Khanna HD. Evaluation of CSF adenosine deaminase activity in tubercular meningitis. J Assoc Physicians India 1999; 47:192-4.

28. Verajit Chotmongkol, Yaovalak Teerajetgul and Chattanong Yodwut. CSF ADA activity for the diagnosis of tuberculous meningitis in adults. Southeast Asian J Trop Med 2006; 37(5):948-52.

29. N.Selvakumar, Vanajakumar, M.Duraipandian et al. CSF ADA and lysozyme levels in the diagnosis of tuberculous meningitis. Ind J Tub 1991; $38: 217-220$. 